\title{
Artikkeli
}

\section{Kaltio-tapaus pilakuvakriisin ylikansallisena muotona}

\begin{abstract}
Artikkelissa tarkastellaan tapahtumaketjua, jonka aiheutti taiteilija Ville Rannan Kaltio-lehdessä julkaistu sarjakuva tanskalaisista Muhammed-pilakuvista ja niiden synnyttämästä monikansallisesta kriisistä vuonna 2006. Tapahtumia analysoidaan pelon käsitteen avulla: miten pelko tuotti ja ohjasi tietynlaista toimintaa? Analyysissa tarkastellaan pelkoon liittyvien tekijöiden ylikansallisuutta, eli sitä, miten myös suomalainen kokemusmaailma sekä sosiaalinen ja poliittinen toiminta ovat osa globaaleja virtauksia. Toisaalta pelkoa tarkastellaan toiminnan lamautumisen kannalta. Artikkelissa esitetään, että itsesensuuri on pelon kautta rakentunutta ennakoivaa toimintaa. Lopuksi arvioidaan pelkoa poliittisten käytänteiden syntymisen kannalta. Pelon politiikkaa ei voi helposti sijoittaa perinteisiin politiikan tutkimuksen kategorioihin, eikä sitä pystytä ennakoimaan kovinkaan suurella varmuudella. Ihmisten tunteisiin ja kokemuksiin liittyvä politiikka ja politiikan teoria ovatkin tapoja ymmärtää ja tehdä tulkintoja ilmiöistä, joihin monet muut politiikan tulkintatavat eivät anna riittäviä vastauksia.
\end{abstract}

AVAINSANAT: Kaltio, Muhammed-pilakuvat, pelko, islam

$\mathrm{V}$ uonna 2006 niin kutsuttu pilakuvakriisi nostatti odottamattoman kansainvälisen poliittisen selkkauksen. Kööpenhaminassa ilmestyvän Jyllands-Postenin kulttuuritoimittaja Flemming Rose tilasi tanskalaisilta taiteilijoilta 12 profeetta Muhammedia esittävää pilakuvaa, jotka julkaistiin lehdessä syyskuussa 2005. Tämän seurauksena Saudi-Arabiassa uskonnolliset johtajat kehottivat boikotoimaan tanskalaisia tuotteita, ja tammikuun 2006 lopussa maa sulki Tanskan-lähetystönsä protestina kuvien julkaisemiselle. Tammikuun aikana protestin ilmaukset alkoivat nopeasti laajeta ja voimistua. Osa yltyi väkivaltaisiksi kahakoiksi erityisesti Pakistanissa, Afganistanissa, Libyassa ja Nigeriassa. Väkivaltaisuuksissa kuoli yli sata ihmistä. Tämän lisäksi Syyrian Damaskoksessa sytytettiin tuleen Tanskan ja Norjan suurlähetystöt sekä hyökättiin eurooppalaisten omistamiin rakennuksiin. Useat islamilaiset ryhmät paheksuivat kuvien julkaisemista ja tanskalaiset muslimijärjestöt järjestivät mielenosoituksia kiinnittääkseen huomiota pilakuvien julkaisuun. Pilakuvia pidettiin rasistisina, islamofobisina ja rienaavina. Niiden tarkoituksena nähtiin olevan Tanskassa asuvien muslimien nöyryyttäminen. Osa eri puolilla maailmaa toimivista muslimijohtajista pyysi protestoijia pysymään rauhallisina, mutta osa puolestaan julisti kostoa 
tanskalaisille ja "lännelle". Konkreettisena vastareaktiona asetettiin tanskalaisia tuotteita ostoboikottiin.

Pilakuvat kokonaisuudessaan tai osa niistä oli julkaistu helmikuun 2006 loppuun mennessä yli 140 lehdessä, jotka ilmestyvät yli 50 maassa, sekä internetissä useissa eri osoitteissa. Jyllands-Posten perusteli julkaisua halullaan osallistua islamia ja itsesensuuria koskevaan keskusteluun. Kuvien julkaisua puolustavat perustelivat kantaansa sananvapauden toteuttamisella ja itsesensuurin välttämisellä. Puolustajien mielestä kuvien tarkoituksena oli avata keskustelua muslimiterrorismista. (Tapauksesta tarkemmin ks. esim. Linjakumpu 2009, 101-139.) Kiistan vaikutukset ylsivät myös pohjoiseen Suomeen: Oulussa julkaistava kulttuurilehti Kaltio julkaisi helmikuussa 2006 verkkosivuillaan Ville Rannan tekemän satiirisen sarjakuvan, joka kuvasi Jyllands-Postenin pilakuviin liittyviä keskusteluja ja reaktioita. Pelko oli sarjakuvan keskeinen teema. Sarjakuvassa piirtäjä muun muassa selittää naamion taakse piiloutuneelle profeetta Muhammedille: "Ei sillä ole mitään arvoa, että ei-muslimi noudattaa Koraanin määräyksiä koska pelkää." Lisäksi sarjakuvassa arvioitiin kriittisesti Suomen valtiojohdon toimintaa pilakuvakriisissä. ${ }^{2}$

Internetissä julkaistua sarjakuvaa kommentoitiin monin eri tavoin. Muun muassa nimimerkki Islaminuskoinen antoi palautetta niin Kaltiolle kuin netissä ilmoittaneille yrityksille. Tietokirjailija Reijo Vallan mukaan Islaminuskoisen viesteissä annettiin ymmärtää, että Kaltio olisi julkaissut alkuperäiset Muhammed-pilakuvat. Nimimerkki myös kysyi, "miksi yritykset haluavat tukea islaminvastaista lehteä laittamalla siihen ilmoituksia." Nimimerkki paljastui pian suomalaiseksi nuoreksi mieheksi, joka oli syystä tai toisesta halunnut sekoittaa tilannetta. ${ }^{3}$ Sarjakuvan julkaisemisen takia Sampo- ja Tapiola-yhtiöt ilmoittivat lopettavansa ilmoittelun Kaltiossa. Oulun opetusviraston työryhmä peruutti puolestaan Ville Rannalta tilatun kuvituksen koululaisille suunnattuun kirjaan J.V. Snellmanin elämästä. Päätoimittaja Jussi Vilkunan kieltäydyttyä poistamasta sarjakuvaa verkkosivuilta hänet erotettiin toimestaan. Pian tämän jälkeen sarjakuva poistettiin.

Sekä pilakuvakriisi että Kaltio-tapaus havainnollistavat huumorin liittyvää poliittisuutta. Pilakuvat ja sarjakuvat ovat uhka sosiaalisille, poliittisille ja uskonnollisille normeille. Vakavuuden avulla voidaan ylläpitää vallankäyttöä ja sosiaalista järjestystä, jolloin huumori edustavaa pakoa valta-asemien alaisuudesta (ks. Le Naour 2001, 265; Davies 2001, 407). Erityisesti ääri-islamilaisuus on pyrkinyt rajaamaan komiikan, huvin ja ilon pois uskonnollisesta julkisuudesta. Esimerkiksi Iranissa, Saudi-Arabiassa tai Taleban-hallinnon aikaisessa Afganistanissa huvista on tullut keskeinen poliittisen taistelun tila (Bayat 2007, 447). Jyllands-Postenin pilakuvat ja Kaltio-lehden sarjakuva ovat osa tätä laajempaa kokonaisuutta, joka liittyy huumorin - ja tätä kautta vallankäytön - problematiikkaan julkisessa islamilaisessa diskurssissa.

Kaltioon liittyvä tapahtumaketju oli alkuperäisen globalisoituneen pilakuvakriisin paikallinen ja kansallinen versio. Tutkimuksellisesti Kaltio-tapaus on kiinnostava, koska se tuo monipuolisesti tutkittuun pilakuvakriisiin ${ }^{4}$ kokonaan uudenlaisen näkökulman. Pilakuvakriisin aikana vallitsevia tapoja hahmottaa tapahtumia olivat muslimien reaktioiden tulkitseminen ja muut islam-lähtöiset tulkinnat. Tässä artikkelissa 
pyritään sen sijaan hahmottamaan, mitä Kaltio-tapauksen kaltaiset tapahtumat merkitsevät ei-islamilaisessa maailmassa, Suomessa. Näin pystytään yhdistämään ylikansallisen politiikan ulottuvuuksia suomalaisiin, paikallisiin ja kansallisiin poliittisiin erityispiirteisiin, muun muassa suomettumisen problematiikkaan. Kaltio-tapaus onkin merkityksellinen esimerkki uudenlaisten, globaalien poliittisten tendenssien vaikutuksista ja seurauksista suomalaisessa yhteiskunnassa.

Kaltio-tapausta voidaan arvioida monesta näkökulmasta. Tapahtumien aikana puhuttiin paljon kulttuurisensitiivisyyteen liittyvistä tekijöistä (muun muassa sanoilla hienotunteisuus, kunnioitus ja vastuu), sananvapaudesta ja rasismista. ${ }^{5}$ Tässä artikkelissa tapahtumaketjua pohditaan pelon käsitteen avulla. Nykyisessä maailmassa pelko on eräs keskeisimpiä kollektiivisia tunteita. Se on myös ihmisten ja ihmisryhmien toimintaa jäsentävä tekijä. Tässä artikkelissa Kaltioon liittyviä tapahtumia analysoidaan nimenomaan tästä näkökulmasta: miten pelko tuotti ja ohjasi tietynlaista toimintaa? Tavoitteena on pohtia, miksi pilakuvakriisin suomalainen versio oli mahdollinen ja miten sen synty voidaan ymmärtää pelon käsitteen avulla. Analyysissa korostuu pelkoon liittyvien tekijöiden ylikansallisuus: myös suomalainen kokemusmaailma ja siihen liittyvä sosiaalinen ja poliittinen toiminta ovat osa globaaleja virtauksia. ${ }^{6}$ Vaikka suomalaisessa yhteiskunnassa islamin merkitys on edelleen varsin minimaalinen, Kaltio-tapaus osoitti yleismaailmallisten islamiin liittyvien pelkojen elävän myös Oulun kaltaisissa syrjäisissä paikoissa. ${ }^{7}$ Analyysissä arvioidaan, miten ja miksi tällainen asetelma syntyi Ville Rannan sarjakuvan vuoksi; millaiseen kontekstiin tilanne on sijoitettava ja mitä se ilmaisee pelon kannalta tulkittuna. Pelon tunteet voivat vaikuttaa poliittiseen toimintaan lamauttavasti. Artikkelissa arvioidaan pelon ja itsesensuurin suhdetta, ja sitä, onko suomalainen yhteiskunta siirtymässä uudenlaisen suomettumisen aikaan. Artikkelin lopussa arvioidaan, millaisia yhteiskunnallisia seurauksia pelolle rakentuvalla politiikalla voi olla.

Artikkeli on luonteeltaan teoreettis-analyyttinen, ei niinkään empiirinen. JyllandsPostenin pilakuvat ja Kaltion sarjakuva ${ }^{8}$ ovat toimineet lähtölaukauksena erilaisille tapahtumaketjuille, joita artikkelissa pyritään tulkitsemaan pelkoon ja muihin kollektiivisiin tunteisiin liittyviin pohdintoihin tukeutuen. Tunteisiin liittyvä kirjallisuus on laajaa; tässä yhteydessä käytetään hyväksi erityisesti politiikan tutkimuksen ja sosiologian piirissä tehtyä tunteiden tutkimusta, jonka avulla pyritään ymmärtämään kollektiivista poliittista toimintaa. ${ }^{9}$

\section{Pelon politiikka ja poliittisen toiminnan selittäminen}

Pelot, riskit ja hätätilan kokemus sävyttävät nykyistä maailmaa ja ihmisten kokemusta elämästä niin Suomessa kuin muuallakin. On tärkeää arvioida, miten tunteet yleensä, tässä tapauksessa erityisesti pelko, toimivat analyyttisenä käsitteenä ihmisten ja kollektiivien toiminnan ymmärtämisessä. Puhun pelosta tunne-käsitteen avulla, joka osaltaan liittyy myös affektin käsitteeseen. Affekti voidaan ymmärtää tiedostamattomana tunteena (esimerkiksi hätä tai ahdistuneisuus), joka voi tulla tiedostetuksi tun- 
teeksi (esimerkiksi pelko). Tällä tavoin "affekti etsii objektia, jotakin johon se voi ankkuroitua ja antaa merkityksen" (Hoggett 2009, 23). Tiedostetun tunteen avulla ihmiset ja yhteisöt pystyvät suuntaamaan toimintaansa (emt. 23, 176). Kaltio-tapauksen tyyppisissä tapahtumaketjuissa pelko ja hätä näyttäytyvät sekä tiedostamattomina affekteina että tiedostettuina tunteina.

Poliittinen toiminta voidaan määritellä päämäärätietoiseksi tekemiseksi, jossa pyritään jonkin ideologian ohjaamana tiettyihin tavoitteisiin. Sen mielekkyys ei synny pelkästään rationaalisen ajattelun kautta, vaan myös tunteisiin ja kokemukseen liittyvät tekijät ovat tärkeitä. Tunteiden merkitys politiikan tutkimuksessa on jäänyt suhteellisesti ottaen vähälle huomiolle: "oikea" politiikka nähdään rationaalisena toimintana, jossa tunteet ovat lähinnä poikkeama normaalitilanteesta (vrt. Ost 2004). Kuten yhteiskuntatieteilijä Ian Burkitt $(2005,694)$ toteaa, mikä tahansa vallan, hallinnon ja politiikan analyysi, joka ei ota huomioon tunteita, sivuuttaa jotain olennaista.

Pelko on keskeinen tunne, niin yksilöllisellä kuin yhteisölliselläkin tasolla. Ilman pelkoa inminen altistuisi monille vaarallisille tilanteille. Jotta tunteiden poliittinen ulottuvuus voidaan ymmärtää, ne pitää nähdä kattavampana kuin pelkästään yksilöllisenä ja "sisäisenä" asiana tai reaktiona ulkoiseen ärsykkeeseen. Tunteita ei pitäisikään sijoittaa pelkästään subjektiviteetin alueelle, sillä olemassa on myös ryhmätunteita tai ryhmän hallitsevia tunteita (Kemper 2002, 56). Tunteet eivät siis ole yksiselitteisesti yksilöllisiä tai kollektiivisia (Ross 2006, 213), vaan sijaitsevat sosiaalisissa suhteissa (Barbalet 2002, 4). Tunteiden politiikkaa ilmentää näin vastavuoroisuus, jossa erilaiset tunteelliset reaktiot vahvistavat toisiaan: "tunteet vaikuttavat tapoihin joilla me vastaamme ja sitoudumme omiin suhteisiimme" (Porter 2006, 97).

Pelko on kohtaamista maailman kanssa: on olemassa jotain, joka uhkaa meitä (Solomon 2007, 29-32; ks. myös Power \& Dalgleish 2008, 172). Kaltio-tapauksessa on kyse nimenomaan kollektiivisesta pelon kokemuksesta, ei niinkään yksilöllisestä, esimerkiksi parisuhdeväkivaltaan liittyvästä pelosta. Näissä tapauksissa pelko on sekä kokemuksellisesti että syntyprosesseiltaan erilainen. Kaltio-tapauksessa median ja muun julkisen sfäärin merkitys on olennainen pelon syntymisessä toisin kuin yksilöiden välillä tapahtuvissa pelon prosesseissa. Filosofi Robert Solomonin mukaan "pelko ei ole pelkoa, ellei se liity johonkin havaittuun vaaraan" (Solomon 2007, 32). Tyypillisesti uhka tai vaara sijaitsee "meidän" ulkopuolella (emt.). Kaltio-tapauksessa pelko liittyi syvimmiltään ääri-islamilaisuuden uhkaan. Pelko on emotionaalinen vastaus uhkaavan - todellisen tai kuvitellun - pelon aistimiseen. Kansainvälisen politiikan tutkijan Dominique Moïsin mukaan pelko johtaa puolusteleviin reaktioihin, jotka paljastavat ja kuvastavat tietyn ihmisen, kulttuurin tai sivilisaation haurautta tietyllä hetkellä (Moïsi 2009, 92). Pelko voi olla vääristynyttä tai liioiteltua, mutta se on samalla "aitoa". Kokemusta ei vääristellä itselleen. (Ks. Solomon 2007, 30-31; Altheide 2006, 423-424.)

Pelkoa on tutkittu monella tieteenalalla. Brandon Hamberin $(2006,129)$ mukaan pelkoa tarkastellaan usein kliinisesti, biologisesti ja pääosin ilman kontekstualisointia. Hänen mukaansa esimerkiksi psykologiassa, sosiaalipolitiikassa ja kriminologiassa pelko näyttäytyy usein yksilölliseksi asiaksi. Pelko yhdistetään muun muassa rikollisuuden pelkoon. Pelon yhteys laajempiin sosiaalisiin ja poliittisiin ulottuvuuksiin on 
jäänyt vähälle akateemiselle huomiolle. Yhteiskuntatieteellisellä ja politiikantutkimuksellisella pelon tarkastelulla on kuitenkin pitkät historialliset taustansa (ks. esim. Kapust 2008). Tunteiden politiikassa ei ole kyse yksilöpsykologiasta, vaan siitä, miten tunteet kollektiivisena tekijänä vaikuttavat politiikkaan ja poliittiseen toimintaan.

Kulttuurintutkija Sara Ahmed tarkastelee pelon merkitystä ihmiskehon kautta. Ahmedin mukaan me pelkäämme sitä, mikä "lähestyy meitä". Ahmedin mukaan pelon kieleen liittyy "uhkien kiihtyminen", mikä aiheuttaa eron syntymisen niiden välille, jotka ovat uhattuna ja jotka uhkaavat. Pelko on tämän prosessin seuraus, ei niinkään sen alkuperä. Pelkoon liittyy "itsen" säilyttäminen, mutta myös "meidän", "elämän, niin kuin me ymmärrämme sen" tai "elämän itsensä" säilyttäminen. Samalla pelkoon liittyy ajallinen ja paikallinen ulottuvuus. Nykyisyyden lisäksi pelko ohjaa käsityksiämme tulevaisuudesta ja yhdistää niihin epävarmuuden tunteen. (Ahmed 2004, 63, 65, 72.)

Pelon suhde toimintaan on politiikan tutkimuksen kannalta keskeinen asia, koska ilman tunteita ei ole motivaatiota, suuntaa eikä luomiskykyä (Mercer 2006, 292). Tunteet ovat näin tiukasti kietoutuneet toimintaan: "Tunne edeltää valintaa (asettamalla mieltymykset arvojärjestykseen), tunne vaikuttaa valintoihin (koska se suuntaa huomiota ja on toiminnan lähteenä) ja tunne seuraa valintaa (joka määrittää, kuinka joku tuntee jonkun valinnasta, ja vaikuttaa preferensseihin)" (Mercer 2005, 94). Emotionaalinen sitoutuminen on siis toiminnan edellytys (Barbalet 2002, 2).

Tunteet osoittavat suunnan arvoihin ja poliittisiin ideaaleihin, ja näin ollen määrittävät sitä, mikä on hyvää ja oikein (Burkitt 2005, 682). Arvot, ideaalit ja ajattelut eivät voi esiintyä "vakumisoidussa rationaliteetissa", vaan sen takana on oltava selkeä emotionaalinen konteksti. Englanninkielisen emotion-sanan etymologia on "siirtää jotain", mikä viittaa muutoksen ajatukseen (Ratner 2000, 5). Pelko yhdistettynä turvallisuuden tarpeeseen tuottaa toimintaa ja pyrkimys saavuttaa tunne turvallisuudesta edesauttaa asioiden esiintuomista ja poliittisten agendojen rakentamista. (Vrt. O’Neill \& Nicholson-Cole 2009, 364.) Toisaalta pelolla voi olla toimintaa halvaannuttava vaikutus, mikä ilmenee esimerkiksi itsesensuurin muodossa.

\section{Pelon ylirajaiset diskurssit}

Kaltio-tapaus oli transnationaalin kriisin paikallinen "toteutuma", jonka kehkeytymistä voidaan tarkastella pelkoon liittyvien diskurssien avulla. Kaltio-tapaus ei todennäköisesti olisi ollut mahdollinen jossain aikaisemmassa yhteiskunnallisessa tilanteessa, mutta 2000-luvun poliittiset asetelmat niin kansainvälisesti kuin kansallisestikin ovat olleet tukemassa siihen liittyvien pelon diskurssien syntymistä. Pelko ja sitä tuottavat pelon diskurssit ovat muuttuvia, ja muotoutuvat tietyn ajan ja paikan luomien reunaehtojen tuottamina ja mahdollistamina. Kaltioon liittyvät tapahtumat kuvastavat pelkoa siitä, että sarjakuvan julkaisemisesta saattaisi nousta kansainvälinen kohu. Kyse on myös uudenlaisten uhkien, turvattomuuden tunteiden ja pelon kokonaisuudesta. Nykyisin turvallisuuden problematiikka on globalisoitunut, ja turvallisuuden kokonai- 
suus on yhä sekavampi ja monikerroksisempi (Hamber 2006, 128). Samalla tavalla myös turvallisuuden puuttumiseen liittyvät pelot ovat globalisoituneet ja tulleet kaikkialle ulottuviksi (Hoffman 2004, 1027). Pelot ja uhkat ovat harvoin kuitenkaan täsmällisesti määrittyviä. Pikemminkin ne ovat diskursiivisia kokonaisuuksia, jotka kuitenkin ohjaavat ymmärrystä sosiaalisista ja poliittisista tilanteista ja toimijoista.

Pelon diskurssien syntyminen tarkoittaa, että yhteiskunnallinen elämä kuvataan vaarallisena, kauhistuttavana ja todellisia tai mahdollisia uhreja sisältävänä (ks. esim. Furedi 2002; Glassner 1999). Mediatutkija David Altheiden (2006, 423) mukaan tällainen symbolinen järjestys kutsuu suojelemaan, valvomaan ja tekemään väliintuloja. Pelko sinänsä ei ole tärkeää sosiaalisessa elämässä, vaan se, kuinka pelko määritellään ja toteutetaan jokapäiväisessä sosiaalisessa vuorovaikutuksessa. Pelon diskurssi voidaan Altheiden mukaan määritellä läpitunkevaksi kommunikaatioksi, symboliseksi tietoisuudeksi ja odotukseksi, että vaara ja riski ovat keskeisiä piirteitä ihmisen fyysisessä ja symbolissa ympäristössä (Altheide 2006, 417; ks. myös Mythen \& Walklate 2006, 123).

Pelon ylirajainen läsnäolo 2000-luvun yhteiskunnallisissa keskusteluissa ja tätä kautta pelon diskurssien syntyminen ei ole sattumanvaraista (Pain 2009, 467). Monet globaalit tai deterritoriaaliset teemat ovat olleet luomassa ja määrittämässä julkista näkökulmaa ja yhteiskunnallispoliittisia suuntaviivoja pelon kokemiselle. Maahanmuutto, yli rajojen kulkevat taudit, finanssikriisit ja erilaiset ympäristöongelmat ovat muodostamassa globaaleja uhan ja pelon diskursseja. Uhkat syntyvät ja leviävät yhä enemmän yli perinteisten kansallisten ja kulttuuristen rajojen. ${ }^{\circ}$ Voidaan puhua globalisoidun pelon metanarratiivista, joka on mukana tieteessä, julkisuudessa, politiikanteossa sekä yksittäisten ihmisten kokemusmaailmassa. Globalisoidun pelon metanarratiivi pyrkii luomaan pelosta kaikkialla läsnä olevan ja kytkeytyneen. Pelko ei ole pelkästään psykologinen, vaan myös sosiaalinen ja tilallinen ilmiö. (Pain 2009, 467; ks. myös Koskela 2009, 29-64; Mythen \& Walklate 2006, 133-134.)

Globalisoitunut pelko ei ole uusi asia, mutta viimeisten vuosikymmenien aikana pelkoon liittyvien maantieteellisten skaalojen laajentuminen sekä pelon diskurssien kiihtyminen, tehostuminen ja hämärtyminen on ollut ilmeisempää kuin aikaisemmin. Pelon transnationaali ulottuvuus viittaa siihen, että pelkoa tuotetaan ja "kuvitellaan" nopeasti yli kansallisten rajojen. Pelkoa tuotetaan muun muassa median, elokuvien, uutisten ja erilaisten mediakommentaattoreiden avulla. Erilaiset toimijaryhmät pääsevät median kautta ääneen, mikä vahvistaa pelkoon liittyvien diskurssien rakentumista, ylläpitämistä ja vahvistumista. Myös elokuvat, kirjallisuus, teatteri ja muu taide voivat olla ylläpitämässä pelkoihin liittyviä narraatioita, jotka juurtuvat yhteisöjen kollektiiviseen muistiin. (Ks. esim. Glassner 2004; Jarymowicz \& Bar-Tal 2006, 377.)

Reaaliaikainen media yhdessä internetin kanssa ovat luomassa ylikansallista mediasfääriä. Pelon diskurssien ylikansallinen rakentuminen onkin riippuvainen median tuottamista mahdollisuuksista. Kysymys ei ole niinkään siitä, että maailma olisi tullut vaarallisemmaksi kuin aikaisemmin, vaan siitä, että pelot ja uhkat saavat huomattavan mediahuomion (Pain 2009, 468-470). Erityisesti välittömän kokemusmaailmamme tavoittamattomissa olevien ryhmien tai alueiden kohdalla median välittämä kuva on 
tärkeä. Media tuottaa ja uudistaa mielikuvia, joiden kautta määrittyy suhtautumistapa kyseisiin inmisiin ja alueisiin. Myös Kaltio-tapaus on pelon diskurssien tuottamista. Sekä Jyllands-Posten että Kaltio ovat itsessään median edustajia ja toisaalta tapaukset elivät median kautta. Lehtien ja television lisäksi internetin merkitys oli olennainen reaktioiden ja kriisin syntymisen kannalta. Kaltio pyrki Rannan sarjakuvan avulla osaltaan reflektoimaan pelkoon liittyviä puhe- ja toimintatapoja, mutta samalla se osallistui - todennäköisesti - tahtomattaan myös itse pelon diskurssien ylläpitämiseen.

Sosiologi Barry Glassner (2004, 820-823) esittää kolme median käyttämää pelon levittämisen tekniikkaa: toiston, erillisten tapausten esittämisen trendinä ja huomion "väärin kiinnittämisen". Toiston avulla pidetään pelkoon liittyvät asiat ja teemat ihmisten mielissä ja ylläpidetään pelkoon liittyviä mielikuvia. Mediassa nostetaan esiin myös erilaisia poikkeustapauksia, joita tulkitaan ikään kuin ne edustaisivat laajempaa kehityskulkua. Tähän liittyy huomion kiinnittäminen virheellisellä tavalla johonkin pelkoa tuottavaan tilanteeseen tai asiaan ilman, että otettaisiin huomioon mahdollisia myönteisiä kehityskulkuja tai näkökulmia, jotka olisivat vastakkaisia pelkoa tuottavalla näkökulmalle."

Nämä pelon levittämisen tekniikat ovat olleet mitä selvimmin esillä myös islamiin, erityisesti 2000-Iuvun islamilaiseen terrorismiin liittyen. 2000-luvun alun islamiin liitetty terrorismidiskurssi on jatkoa kylmän sodan jälkeiselle tilanteelle. Tuolloin Neuvostoliiton ja kommunismin uhka alkoi väistyä ja tilalle tuli islamin uhka (ks. esim. Joseph 2008, 63). Lähi-idän epävakaa poliittinen kehitys, erityisesti Palestiinan konflikti, on pitänyt yllä islamiin ja islamilaisiin maihin liitettäviä uhkakuvia. Islamiin liittyvät uhkat ovat olleet tiedotusvälineissä laajasti esillä. Islamilaisesta terrorismista ja siihen liittyvästä terrorisminvastaisesta sodasta on tullut yksi 2000-luvun alun keskeisiä uhkien ja pelkojen lähteitä. Islamiin liittyvää pelon diskurssia ovat tuottaneet monet toimijat, mutta al-Qaidan merkitys on erityisen olennainen. Se on onnistunut globaalien pelkoa tuottavien diskurssien luomisessa. (Ks. Semmerling 2008; Sajid 2005; Linjakumpu 2009, 88-100; Linjakumpu 2007a; Linjakumpu 2007b.) Globaalien diskurssien ja toiminnan kääntöpuolena ovat olleet valtioiden sisällä tapahtuvat terroriteot ja niiden uhka. Tietoisuus ylikansallisen terrorismin olemassaolosta lisää pelkoa myös paikallisella tasolla (vrt. esim. Sanadjian 2006).

Al-Qaidan tai vastaavien ryhmittymien toimintaa on pidetty poikkeuksellisena verrattuna aikaisempaan terrorismiin tai ääri-islamistisen toiminnan muotoihin. Tämä on ollut osaltaan luomassa kokemusta siitä, että "maailma on muuttunut iäksi" (Mythen \& Walklate 2006, 126). Kaltio-tapaus on tyypillinen globalisoituneen ja verkostoituneen maailman ilmenemismuoto. Erilaiset islamiin liittyvät diskurssit ovat olleet luomassa mielikuvien verkostoa, jossa asiat kytkeytyvät toisiinsa, eikä niitä voi paeta maantieteellisesti (ks. tarkemmin Linjakumpu 2009, 37-46). Oulu tai mikä muu paikka tahansa voi olla globaalien pelkodiskurssien näyttämö. Tanskalaisen pilakuvakriisin suomalainen versio on kytkeytynyt näihin yleisempiin islamiin liittyviin pelon diskursseihin, jotka saivat uutta pontta tanskalaisesta kriisistä. Tässä yhteydessä voidaan puhua kaupunkimaantieteen tutkijan Hille Koskelan (2009, 61-62) tavoin konfliktien urbanisoitumisesta. Poliittiset kriisit ja niihin liittyvät uhkat tapahtuvat yhä enemmän 
kaupungeissa, tavallisten ihmisten keskuudessa. Kansainvälinen politiikka ja ihmisten arki sekoittuvat uudenlaisissa uhkien ja pelkojen kokonaisuuksissa.

Dominiqüe Moïsin $(2009,97)$ mukaan pelko on nykyisin Euroopassa vallitsevin kansainvälispoliittinen "väri" eli pelon tunne määrittelee eurooppalaisia yhteiskuntia. Pelkoa ruokkii hänen mukaansa "toiseuden" kasvaminen demografisesti ja maantieteellisesti Euroopassa. Kulttuurista moninaisuutta ei Moïsin mukaan nähdä Euroopan valtioissa enää hyvinvoinnin ja keskinäisen vaurastumisen lähteenä, vaan pikemminkin sen nähdään horjuttavan sisäistä tasapainoa. Näihin pelkoihin kytkeytyy myös islamilaisen terrorismin pelko. Eurooppa ei ole vain potentiaalisten iskujen kohde, vaan myös terrorismin tukikohta (emt., 102-104). Moïsin esittämiin näkökulmiin nivoutuvat myös pilakuvakriisiin ja Kaltio-tapaukseen liittyvät tapahtumat ja reaktiot. Ali Hussainin $(2007,115)$ mukaan Jyllands-Postenin kuvien julkaisun taustalla oli pelko muslimien suorittamasta väkivallasta omalla maaperällä.

Moïsi arvioi pelon ja epävarmuuden suhdetta. Hän esittää, että ensimmäisen kerran yli kahteen vuosisataan länsi ei enää ole kaiken keskus, vaan potee omasta haavoittuvuudesta ja keskusaseman menetyksestä johtuvaa identiteettikriisiä. Hänen mukaansa näyttää siltä, että länttä alistavat voimat eivät ole lännen kontrollissa. Moïsi yhdistää lännen kokeman identiteettikriisin nimenomaan pelon tunteeseen. Tulevaisuuden määrittelyn mahdollisuuden menettäminen on hänen mukaansa pelon lähde kaikkialla länsimaissa. Pelon päähänpiintymä on Moïsin mukaan vakava haitta ihmisen kyvylle olla vuorovaikutuksessa toisten kanssa. (Moïsi 2009, 91-93; ks. myös Ahmed 2004, 72.)

Samalla kun islamilaisiin toimijoihin liittyvä väkivaltaisuuden diskurssi on saanut laajaa huomiota, on pyritty korostamaan islamin monimuotoisuutta sekä problematisoimaan islamin ja terrorismin välistä suhdetta. (Ks. esim. Wilkins 2009, 561; Weimann 2008, 72; Powers 2008, 339-340.) Tosin Sara Ahmed puhuu tässä yhteydessä metonymioista eli kielikuvista, joissa tapahtuu merkitysten vaihtoa. Hänen mukaansa niiden avulla voidaan yhdistää esimerkiksi sanat "terroristi" ja "islam" yhteen - myös niissä tapauksissa, joissa pyritään välttämään kyseistä yhdistelmää. Ahmedin mukaan ilmaukset kuten "tämä ei ole sota islamia vastaan" esiintyvät muun muassa "islamilainen terrorismi" -tyyppisten ilmausten kanssa (Ahmed 2004, 76). Tämän vuoksi - ja kieltämisestä huolimatta - syntyy linkki islamin ja terrorismin välille, vaikka tarkoitusperä olisi toinen.

\section{Suomalainen itsesensuuri transnationaalissa kontekstissa: suomettumisen uusi aikakausi?}

Pelon suhde poliittiseen toimintaan voi olla kahdenlainen. Pelko voi olla tuottamassa toimintaa ja muovaamassa yhteiskunnallista todellisuutta sekä sen moraalista kehystä. Toisaalta se voi myös ehkäistä ja lamauttaa toimintaa. Pelko voi olla niin yhteiskunnallista pysyvyyttä ylläpitävää kuin uutta luovaa. Pelon ilmapiiri on omiaan luomaan muutosvastaista ilmapiiriä. (Vrt. Hamber 2006, 139.) Vaarassa olevat yksi- 
löt tapaavat sietää vähemmän muutosta kuin ilman vaaran tunnetta elävät (Huddy 2004, 802). Tämä puolestaan johtaa kasvaneeseen stereotypioihin tukeutumiseen ja vihamielisyyteen ulkopuolisia kohtaan.

Pilakuvakriisin ja Kaltio-tapauksen taustalla olevat uhkakuvat aiheuttivat pelkoa ihmisryhmissä, jotka olivat huolissaan tai peloissaan omasta, läheistensä tai laajemman yhteisön turvallisuudesta. Jotta uhkaa voidaan käsitellä ja torjua, asiat pyritään pitämään nykyisellään ja pysymään erossa uhkia luovista tilanteista. (Vrt. Ahmed 2004, 77-79.) Kaltio-tapauksesta voi tulkita halua pitää asiat ennallaan. Tapaukseen liittyvät toimijat - mainostajat ja muut sidosryhmät - eivät halunneet politisoida kulttuureihin tai uskontoihin liittyviä tekijöitä, vaan pyrkivät pitämään ne poliittisten agendojen ulkopuolella. Taloudellisten toimijoiden näkökulmasta status quon ylläpitäminen saattaa olla olennaisempaa kuin joutuminen sekoitetuksi poliittisiin prosesseihin. Kaltio-tapauksessa tämä tarkoitti sitä, että laajempi kohu olisi kytkenyt taloudelliset toimijat mahdollisesti hyvin hankaliin ja laajamittaisiin poliittisiin kriiseihin, jotka olisivat saattaneet vaikeuttaa yritysten taloudellista toimintaa. Sama pätee myös muihin päätoimittajan irtisanomiseen tai Rannan työtilausten peruuttamiseen liittyviin toimijoihin. Pelko on voinut olla selvästi tiedostettua tai tiedostamatonta affektinomaista hätää tai uhkaa, johon on haluttu reagoida.

Tässä yhteydessä pelon suhde itsesensuuriin on merkityksellinen. Itsesensuuri on konkreettinen muoto passiivisesta poliittisesta toimijuudesta. Sekä Jyllands-Postenin pilakuviin että Rannan sarjakuvaan liittyneissä keskusteluissa itsesensuuri tuli voimakkaasti esille. Jyllands-Postenin pilakuvien julkaiseminen oli kulttuuritoimittaja Rosen mukaan "häiritsevän itsesensuurin ketjun kulminaatio"12. Kuvien julkaisemisella haluttiin nostattaa keskustelua islamista, siihen liittyvistä peloista ja itsesensuurin perinteestä (Powers 2008, 349; Tangherlini 2008). Jyllands-Posten pyrki siis omalla toiminnallaan haastamaan itsesensuurin perinteen islamiin liittyen, samoin kuin Rannan sarjakuva. Seurauksena oli, että Rannan sarjakuva yhtäältä aiheutti itsesensuuria ja toisaalta synnytti keskustelua itsesensuurin syntymisestä. Sarjakuvan vastaanottoon liittyvässä keskustelussa itsesensuuriin liittyvä kritiikki olikin voimakasta. ${ }^{13}$ Myös ulkomaisissa medioissa, muun muassa ranskalaisessa Le Mondessa ja saksalaisessa Frankfurter Allgemeine Zeitungissa, arvioitiin Rannan sarjakuvan vastaanottoa itsesensuurin ja suomettumisen näkökulmista (ks. Ulkoministeriö 2006).

Itsesensuuri ei ole uusi asia islamiin liittyvissä, ylikansallisissa kriiseissä. Kirjailija Salman Rushdien vuonna 1988 ilmestynyt teos The Satanic Verses (Saatanalliset säkeet) aiheutti laajan kansainvälisen kohun, johon liittyi muun muassa Iranin johtajan ajatollah Khomeinin asettama kuolemanrangaistuksen sisältävä fatwa (eli uskonnollinen määräys). Uhka kohdistui myös kustantajiin, kääntäjiin ja kirjakauppoihin, jotka olivat tekemisissä kirjan julkaisun ja myynnin kanssa. Kirjan ilmestyminen aiheutti mielenosoituksia ja yhteenottoja eri maissa sekä hyökkäyksiä asianomaisia ihmisiä kohtaan, olkoonkin että Rushdie itse on säilynyt vahingoittumattomana. Monissa islamilaisissa maissa kirja oli ja on edelleen kiellettyjen listalla ja ei-islamilaisissa maissa kirjan käsittelemiseen on liittynyt itsesensuurin piirteitä. (Ks. Linjakumpu 1999, 232-234.) 
Kuten Rushdien tapaus osoittaa, itsesensuuri on lähellä sensuuria. Sensuuri voi johtua moraalisesta närkästyksestä ja laittomasta sisällöstä. Toisaalta sensuuri ja itsesensuuri nivoutuvat myös turvallisuuteen ja siihen kohdistuviin uhkiin: sensuuri tarjotaan yleisölle turvallisuuden nimissä (DeGenevieve 2007, 164). Kaltio-tapauksessa itsesensuuri liittyi islamin uskonnollisiin representaatioihin eli siihen, miten profeetta Muhammedia kuvataan. Itsesensuuri merkitsee olemassa olevan sekä tulevan toiminnan tukahduttamista. Samalla siinä luodaan käytäntöjä myös muiden tekemisille. Itsesensuuria muun muassa elämänkerroissa tutkinut Judy Sharkey $(2004,507)$ kysyykin, "itseään sensuroimalla, enkö myös tahattomasti sensuroi tai vaienna muita?"

Itsesensuuri on yksi tapa ylläpitää poliittista stabiliteettia. Suomalaisessa yhteiskunnassa ilmeisenä esimerkkinä itsesensuurista on kylmän sodan aikainen toimintakulttuuri, joka liittyi nimenomaisesti Neuvostoliiton suhteisiin. Suomettumisen käsite sisältää peloissaan olon, itsesensuurin ja opportunismin ulottuvuuksia. Näitä ulottuvuuksia on pyritty suomalaisessa yhteiskunnassa purkamaan viimeisten kahden vuosikymmenen aikana. Kaltio-tapauksessa ja sitä edeltäneessä Muhammed-pilakuvakriisissä itsesensuurin vaikutukset liittyivät toisaalta paikalliseen toimintaan, mutta toisaalta myös kansalliseen tai valtiolliseen toimintakulttuuriin. Transnationaali kokemus ja tilanne tuovat oman sävynsä itsesensuurin muodostumiseen, sillä potentiaalisesti kaikki asiat voivat tulla itsesensuurin kohteeksi. On aiheellista kysyä, aiheuttaako itsesensuurin uusi transnationaali aikakausi suomalaisessa yhteiskunnassa uudenlaista suomettumista. Transnationaalin asetelman luoma itsesensuuri voi näyttäytyä opportunismina kuten "ei häiritä ketään maailmalla, ei aiheuteta ongelmia Suomelle".

Itsesensuuri on yksi tapa tulkita poliittisen toiminnan lamaantumista tai passivoitumista. Se voi olla joissakin tilanteissa helposti havaittavaa ja todennettavaa, mutta toisaalta sitä harvoin tunnistetaan tai tunnustetaan omasta toiminnasta (ks. esim. Oates 2007, 1292). Tämä pitää paikkansa myös Kaltion tapauksessa. Näkökulmaa vaihtelemalla voitaisiin puhua kulttuurisesta sensitiivisyydestä, sosiaalisesta vastuullisuudesta, poliittisesta korrektiudesta tai turvallisuuden hakemisesta ja ylläpitämisestä.

Demokratian ja median välisiä yhteyksiä tutkinut Sarah Oates (2007, 1281-1282) puhuu sosiaalisesta vastuullisuudesta, jonka tarkoituksena on suojella yhteiskuntaa vaikkapa huonolta maulta tai väkivaltaan tai paniikkiin johtavalta informaatiolta. Sosiaalisen vastuullisuuden malli pyrkisi yhteiskunnalliseen konsensukseen ja harmoniaan. Tässä mielessä Kaltio-sarjakuvaan kohdistuvat reaktiot voitaisiin siis tulkita yhteiskuntarauhan ylläpitämiseksi, jonkinlaiseksi proaktiiviseksi tavaksi suhtautua ongelmalliseen tilanteeseen. Sosiologit Gabe Mythen ja Sandra Walklate $(2006,138)$ puhuvat puolestaan turvallisuutta tavoittelevasta käytöksestä. Itsesensuuri voi liittyä myös poliittisen korrektiuden ideaan (Hyde \& Ruth 2002, 242). Suomalaisessa yhteiskunnassa poliittista korrektiutta ei ole pidetty yhtä merkittävänä ilmiönä kuin vaikkapa Pohjois-Amerikassa. Muhammed-pilakuviin reagoiminen Suomessa voitaisiin tulkita myös pyrkimyksenä käsitellä hankalaa tilannetta poliittisesti korrektilla tavalla.

Nähtäväksi jää aiheuttaako yhä syvemmälle menevä kulttuurinen ja poliittinen globalisoituminen myös suomalaisessa kontekstissa edellä mainittujen "poliittisten strategioiden" leviämistä. Olipa Kaltio-tapauksen tulkinta mikä tahansa, olisi oltava tietoi- 
nen tällaisten toimintatapojen tai intentioiden suhteesta kollektiivisiin tunteisiin. Muutoin voi olla vaikea käsitellä esimerkiksi islamiin liittyviä pelko- ja uhkatekijöitä, jotka vaikuttavat poliittisten ja sosiaalisten suhteiden ja toimintatapojen muotoutumiseen.

\section{Pelon diskurssit ja politiikan uudet käytännöt}

Islamiin liittyvät ylirajaiset diskurssit toivat Kaltio-tapauksessa pelon paikalliselle ja kansalliselle tasolle. Minkälaisen tulevaisuusorientaation pelon diskurssit voivat luoda poliittisen toiminnan suhteen? Konfliktien jälkeisiä yhteiskuntia tutkinut Brandon Hamber $(2006,129)$ korostaa pelon tutkimisen merkitystä erityisesti poliittisen muutoksen kontekstissa. Voikin kysyä, onko Suomi henkisessä ja kulttuurisessa muutostilassa, jossa haetaan uudenlaisia poliittisen elämän lähtökohtia ja legitimaation perusteita. Muutostilassa on mahdollista tehdä poliittisia ja ideologisia interventioita, joilla rakennetaan uudenlaista poliittista kulttuuria.

On oletettavaa, että transnationaali islam ja siihen liittyvät uhkat artikuloituvat yhä enemmän suomalaiseen arkipäivään ja politiikan käytäntöihin, vaikka tilanne Suomessa ei olisi konkreettisesti kovin paljoa muuttunut. Globalisoitumisen ja yhä tiiviimmän sosiaalisen, poliittisen ja kulttuurisen verkostoitumisen takia Suomeen yltävät jo muualla Euroopassa vaikuttavat tendenssit. Kaltio-tapaus on ilmentymä ylikansallisista virroista, joissa globaalin islamistisen diskurssin vaikutukset leviävät syrjäisimpiinkin valtioihin.

Pelkoon liittyy kosketus tai läheisyys pelkoa tuottavan objektin kanssa (ks. Ahmed 2004, 68). Islam ideologisena kokonaisuutena ja muslimit sitä edustavina kollektiiveina ovat pelon objekteja, jotka konkreettisella olemassaolollaan muistuttavat vaarasta. Suomalaisen yhteiskunnan käytäntöihin ja diskursseihin liitettynä vaara ilmenee esimerkiksi muslimisiirtolaisuuden muodossa. Maahanmuuttokriittinen diskurssi saakin voimansa tästä läsnäolon tuomasta uhan ja vaaran tunteesta - riippumatta sen todellisuuspohjasta.

Uhka ja siihen mahdollisesti liittyvä moraalinen paniikki ovat omiaan aiheuttaman vihamielisyyttä uhkan aiheuttajaa kohtaan (ks. esim. Schinkel 2008, 737). Kaltio-tapauksessa pelon aiheuttama moraalinen paniikki ja vihanosoitukset muodostuivat monimutkaisemmin. Pelon kohde ei ollut sinänsä Kaltio tai Rannan sarjakuva, vaan taustalla vaikuttava islamin ja islamismin pelko. Pelosta aiheutuvat reaktiot eivät kuitenkaan kohdistuneet muslimeihin suoraan, vaan Kaltioon ja sarjakuvapiirtäjään. Oletettu asetelma kääntyi siis toiseksi.

Pelon diskurssit muuttavat helposti olemassa olevia ystävä-vihollinen-liittoumia. Pelko antaa uusille toimijaryhmille mahdollisuuksia tuoda näkemyksiään esiin. Tässä mielessä ääri-islamilainen diskurssi on onnistunut luomaan globaalia agendaa, jossa sekoitetaan poliittisia rakenteita ja suhteita. Suomessa asuva Irakin kurdi Husein Muhammed esittikin eräässä blogikirjoituksessaan, että ääriryhmittymillä on olemassa "jonkinlainen epäpyhä allianssi: ne lisäävät toistensa kannatusta ja vahvistavat toisiaan"14. Hänen mukaansa islamisteilla ja äärioikeistolla on sama tavoite: 
[E]simerkiksi ääri-islamilaisten tekemät terrori-iskut lisäävät ennakkoluuloja ja suoranaista vihaa muslimeja kohtaan. [...] Iskut lisäävät avoimesti muslimivastaisten äärioikeistolaisten puolueiden ja liikkeiden kannatusta länsimaissa. Nämä liikkeet lietsovat vihaa kaikkia muslimeja kohtaan, mikä voi johtaa myös maltillisten, aiemmin hyvinkin länsimielisten muslimien radikalisoitumiseen. Näin lännenvastaisuus lisääntyy muslimien keskuudessa samalla kun muslimivastaisuus yleistyy länsimaalaisten keskuudessa. ${ }^{15}$

Muhammedin mukaan "äärioikeisto lietsoo pelkoa, että vahva islam ja voimakkaasti kasvava muslimiväestö syrjäyttävät eurooppalaisen kulttuurin ja kristinuskon"16. Pelon avulla pyritään omien ajatusten esiintuomiseen ja legitimaation saavuttamiseen. Äärioikeistolaisten tai maahanmuuttokriittisten toimijoiden lisäksi suomalaiset konservatiiviset uskonnolliset piirit pystyvät hyödyntämään pelkoa samantyylisesti omassa toiminnassaan. Lisäksi on huomattava, että samalla tavalla myös äärimuslimit voivat saada pelon ilmapiirin kehittymisestä voimaa omalle toiminnalleen.

Pelon ilmapiiri vaikuttaa sosiaaliseen luottamukseen ja epäilys tavalla tai toisella sisäryhmään kuulumattomien suhteen heikentää luottamusta väestöryhmien välillä (Burt 2006, 40, 46). Pelon politiikka ja luottamukseen perustuva politiikka näyttäytyvätkin vastakkaisina (ks. Gore 2004, 792; Mason 2006); "rasittavissa tilanteissa pelko kumoaa toivon" (Jarymovicz \& Bar-Tal 2006, 368). Vaikka kyse ei olisi varsinaisista väkivaltaa sisältävistä tilanteista, luottamuksen vähentyminen yhteiskunnassa tekee tilaa epäluuloon ja pelkoon perustuvalle toiminnalle. (Ks. myös Koskela 2009, 15-16, 18-19.) Myös Kaltio-tapaus toi esiin pelkoon rakentuvan sosiaalisen paniikin, jossa ylikansalliset tapahtumaketjut vaikuttivat tilanteen syntymiseen.

Pelolla hallitsemisen ja pelottelun avulla legitimoidaan omaa olemassaoloa ja ideologioita. Pelko voi tuottaa toimintaa tai ohjata aiempaa poliittista toimintaa ja ideologiaa uuteen suuntaan. Tutkimuksissa on tarkasteltu muun muassa pelon käyttämistä poliittisesti hyödyksi valtaapitävien toimesta. Pelon avulla hallitessa voidaan oppositioryhmiä pitää hajaannuksessa ja legitimoida omaa vallankäyttöä (ks. esim. Burt 2006; Hyndman 2007). Islamilaisiin uhkakuviin liittyen Yhdysvaltojen hallinnon toiminta syyskuussa 2001 tapahtuneiden terrori-iskujen jälkeen on saanut huomiota myös tässä suhteessa. Erityisesti Yhdysvaltain presidentin George W. Bushin toimia on arvioitu pelolla hallitsemisen kannalta (ks. esim. Gore 2004, 780).

Äärioikeistolaiset ideologiat niin Suomessa kuin muuallakin Euroopassa saavat poliittista voimaa ja perusteluja pelkoon, uhkiin ja turvallisuuteen liittyvistä ulottuvuuksista. Pelko siis mahdollistaa erilaisten sosiaalisten ja poliittisten diskurssien kontrollin, manipuloinnin ja yleistämisen. Pelkoa voidaan ohjailla legitimoinnin, sulkemisen ja tulkitsemisen avulla (Shirlow \& Pain 2003, 15). Toisin sanoen pelon rakentaminen voi olla tietoista toimintaa, jossa joitakin asioita vahvistetaan ja toisia ulkoistetaan pelon diskurssien syntymisen vuoksi. Voidaankin ajatella, että kollektiivisella tasolla tietyt ja tiettyjen ihmisryhmien pelot voivat ohjautua koko yhteiskunnan peloiksi, mikä ilmeni vahvasti myös Kaltio-tapauksessa.

Pelkoa tuottavan objektin kohtaaminen sisältää Ahmedin mukaan samalla liikkumisen kohti "rakastettua kohdetta muodostamalla kodin tai suljetun tilan" (Ahmed 
2004, 68). Tämä viittaa kysymykseen siitä, kenellä tai millä ryhmillä on pääsy tähän jaettujen diskurssien piiriin, kenet jätetään näiden poliittisten diskurssien ja koalitioiden ulkopuolelle. Pelko tuottaa koalitioita, mutta myös ulossulkemisia. Suomessa tämä liittyy esimerkiksi maahanmuuttajien integroitumiseen suomalaiseen yhteiskuntaan. Ulkoisen uhkan korostaminen on pelon luomisessa ja siihen liittyvissä turvallisuusratkaisuissa keskeistä. Uhkien avulla voidaan perustella myös erilaisia poliittisia toimenpiteitä (ks. Huddy ym. 2007, 131-132; Mythen \& Walklate 2006, 127; Oates 2006, 425).

Pelosta nouseva politiikka ei sijoittaudu selviin kategorioihin, eikä sitä pystytä ennakoimaan kovinkaan suurella varmuudella. Pelon politiikka tuottaa julkista sfääriä, jossa poliittiset koalitiot ja "diskursiiviset lähentymiset" yllättävienkin yhteiskunnallisten toimijoiden välillä voivat olla mahdollisia. Suomalainen kansallinen ja paikallinen politiikka on siis yhä enemmän ennakoimattomien transnationaalien poliittisten virtausten areena. Pilakuvakriisin ja Kaltio-tapauksen suomalaiset reaktiot osoittavat selvästi, että perinteisen resurssienjakopolitiikan tai valtapolitiikan avulla ei pystytä tulkitsemaan tämän tyyppisiä kansallisia poliittisia tilanteita, vaan tarvitaan uudenlaisia lähestymistapoja ja analyyttisia välineitä tulkinnan avuksi. Tunteisiin ja kokemuksiin liittyvä politiikan teoria onkin tapa ymmärtää ja tehdä tulkintoja ilmiöistä, joihin perinteiset tulkintatavat eivät anna riittäviä vastauksia.

\section{Viitteet}

$1 \quad$ Kaltio on vuonna 1945 perustettu erityisesti Pohjois-Suomeen keskittyvä mielipide- ja kulttuurilehti.

2 Muhammed, pelko ja sananvapaus. Saatavilla: http://www.villeranta.com/sarjakuvat/nettijulkaisut/ muhammed-pelko-ja-sananvapaus/2 (luettu 11.8.2010).

3 Kaltion Muhammed-kohu helmikuussa 2010. Pois työpöydältä -blogi, 27.2.2010. Saatavilla: http:// poistyopoydalta.blogspot.com/2010/02/kaltion-muhammed-kohu-helmikuussa-2006.html (luettu 12.8.2010).

$4 \quad$ Pilakuvakriisiin liittyvää mediatutkimusta ovat tehneet esimerkiksi Hakam (2009) ja Meer \& Mouritsen (2009). Pilakuvakriisin suhdetta muslimien ja ei-muslimien väliseen kanssakäymiseen ovat tarkastelleet muun muassa Lægaard (2009), Levey \& Modood (2009), Miera \& Pala (2009) ja Rostbøll (2009). Poliittisen toiminnan kannalta pilakuvakriisiä ovat tutkineet muun muassa Larson \& Lindekilde (2009), Olesen (2009) ja Sløk (2009).

5 Katso esimerkiksi: Sampo ja Tapiola pelästyivät Muhammed-kuvia (Helsingin Sanomat 24.2.2006); Kaltion päätoimittaja sai potkut Muhammed-sarjakuvan takia (YLE-uutiset 24.2.2006).

6 Tässä artikkelissa käytetään ylikansallinen-käsitettä. Käsite viittaa rakenteisiin, prosesseihin ja instituutioihin, jotka ylittävät kansalliset rajat eivätkä palaudu mihinkään valtioihin. Ylikansallinen eroaa näin monikansallisen tai kansainvälisen käsitteistä, joissa kansallisen taso eri valtioineen on edelleen määräävä tekijä. Transnationaalinen-käsite on verrattavissa ylikansallisen käsitteeseen. Globaalin käsitettä puolestaan käytetään viittaamaan tilanteisiin, jossa halutaan korostaa tietyn ilmiön tai asian maailmanlaajuisuutta.

7 Tässä yhteydessä on korostettava, että Kaltio-kohu ei ollut muslimien synnyttämä kuten JyllandsPostenin kohdalla vaan "kantasuomalaisten" itsensä rakentamana. Lisäksi on huomattava, että Kaltion sarjakuva oli paljon maltillisempi kuin monet esimerkiksi muslimien itsensä tekemät, islamiin liittyvät pilapiirrokset tai sarjakuvat.

8 Juha Ridanpää (2009) on tutkinut Rannan sarjakuvaa huumorin ja geopolitiikan kannalta. Yleisemmin pilakuvien ja sarjakuvien poliittisuudesta katso esimerkiksi Refaie (2009).

9 Haluan lämpimästi kiittää Oulun yliopiston tutkijatohtori Juha Ridanpäätä Kaltio-tapaukseen liittyvistä keskusteluista ja ajatustenvaihdosta. 
10 Pelon ja uhan narratiivien syntymiseen liittyy myös kansainvälisen politiikan tutkimuksessa paljon käsitelty turvallistamisen problematiikka (ks. esim. Buzan ym. 1998).

11 Glassnerin tutkimuskohteena on yhdysvaltalainen media, mutta hänen näkökulmansa sopii myös eurooppalaiseen ja suomalaiseen kontekstiin.

12 Why I published those cartoons. Jp.k, 19.2.2006. Saatavilla: http://jp.dk/uknews/culture/article169262.ece (luettu 7.8.2010).

13 Katso esimerkiksi http://www.kvaak.fi/keskustelu/index.php?PHPSESSID=ab29cc277d2ca7667C560f8508 dgf6fb\&topic=5787.0; http://www.parnasso.fi/index.php?itemid=162.

14 Islamisteilla ja äärioikeistolla on sama tavoite. Blogi, 27.4.2010. http://huseinmuhammed.blogit. uusisuomi.fi/2010/04/27/islamisteilla-ja-aarioikeistolla-on-sama-tavoite/ (luettu 11.8.2010).

15 Emt.

16 Emt.

\section{Kirjallisuus}

Ahmed, Sara (2004). The cultural politics of emotion. New York: Routledge.

Altheide, David L. (2006). Terrorism and the politics of fear. Cultural Studies - Critical Methodologies 6:4, 415-439.

Barbalet, Jack (2002). Introduction: why emotions are crucial. Teoksessa: Barbalet, Jack (toim.). Emotions and Sociology. Oxford: Blackwell Publishing, 1-9.

Bayat. Asef (2007). Islamism and the Politics of Fun. Public Culture 19:3, 433-459.

Burkitt, Ian (2005). Powerful Emotions: Power, Government and Opposition in the 'War on Terror'. Sociology 39:4, 679-695.

Burt, Jo-Marie (2006). "Quien habla es terrorista". The political use of fear in Fujimori's Peru. Latin American Research Review 41:3, 32-62.

Buzan, Barry; Wæver, Ola \& de Wilde, Jaap (1998). Security: A new framework for analysis. Boulder: Lynne Rienner Publishers.

Davies, Christie (2001). Humour is not a Strategy in War. Journal of European Studies 31:123, 395-412.

DeGenevieve, Barbara (2007). Censorship in the US or fear and loathing of the arts. Social Identities 13:2, 159173.

Furedi, Frank (2002). Culture of fear. Risk-taking and the morality of low expectation. London: Continuum.

Glasnerr, Barry (1999). The culture of fear. New York: Basic Books.

Glassner, Barry (2004). Narrative techniques of fear mongering. Social Research 71:4, 819-826.

Gore, Al (2004). The politics of fear. Social Research 71:4, 779-798.

Hakam, Jamila (2009). The 'cartoons controversy': a Critical Discourse Analysis of English-language Arab newspaper discourse. Discourse Q Society 20:1, 33-57.

Hamber, Brandon (2006). Flying flags of fear: The role of fear in the process of political transition. Journal of Human Rights 5:1, 127-142.

Hoffmann, Stanley (2004). Thoughts on fear in global society. Social Research 71:4, 1023-1036.

Hoggett, Paul (2009). Politics, identity, and emotion. Boulder: Paradigm Publishers.

Huddy, Leonie (2004). Fear and how it works: Science and the sciences. Social Research 71:4, 801-805.

Huddy, Leonie; Feldman, Stanley \& Weber, Christopher (2007). The political consequences of perceived threat and felt insecurity. The ANNALS of the American Academy of Political and Social Science 614, 131-153.

Hussain, Ali J. (2007). The media's role in a clash of misconceptions: The case of the Danish Muhammad cartoons. The Harvard International Journal of Press/Politics 12:4, 112-130.

Hyde, Cheryl A. \& Ruth, Betty J. (2002). Multicultural content and class participation: Do students self-censor? Journal of Social Work Education 38:2, 241-256.

Hyndman, Jennifer (2007). The securitization of fear in post-tsunami Sri Lanka. Annals of the Association of American Geographers 97:2, 361-372.

Jarymowicz, Maria \& Bar-Tal, Daniel (2006). The dominance of fear over hope in the life of individuals and collectives. European Journal of Social Psychology 36:3, 367-392.

Joseph, Sarah (2008). Living in a culture of fear: A Muslim perspective. European Judaism 41:1, 62-68. 
Kapust, Daniel (2008). On the ancient uses of political fear and its modern implications. Journal of the History of Ideas 69:3, 353-373.

Kemper, Theodore D. (2002). Predicting emotions in groups: some lessons from September 2001. Teoksessa: Barbalet, Jack (toim.). Emotions and Sociology. Oxford: Blackwell Publishing, 53-68.

Koskela, Hille (2009). Pelkokierre. Pelon politiikka, turvamarkkinat ja kamppailu kaupunkitilasta. Helsinki: Gaudeamus.

Larsson, Göran \& Lindekilde, Lasse (2009). Muslim claims-making in context. Comparing the Danish and the Swedish Muhammad cartoons controversies. Ethnicities 9:3, 361-382.

Le Naour, Jean-Yves (2001). Laughter and Tears in the Great War: the Need for Laughter/guilt of Humour. Journal of European Studies 31:3-4, 265-275.

Levey, Geoffrey Brahm \& Modood, Tariq (2009). The Muhammad cartoons and multicultural democracies. Ethnicities 9:3, 427-447.

Lægaard, Sune (2009). Normative interpretations of diversity The Muhammad cartoons controversy and the importance of context. Ethnicities 9:3, 314-333.

Linjakumpu, Aini (1999). Poliittinen islam. Helsinki: Like \& Suomen Rauhantutkimusyhdistys.

Linjakumpu, Aini (2007a). Al-Qaida ja globaalin terrorismin menestystarina. Sosiologia 44:3, 217-232.

Linjakumpu, Aini (2007b). Tunteiden politiikka al-Qaidan toiminnassa. Teoksessa: Laitinen, Kari (toim.). Tuhat ja yksi uhkaa - tulkintoja terrorismista. Poliisiammattikorkeakoulun tiedotteita 66. Tampere: Poliisiammattikorkeakoulu, 75-87.

Linjakumpu, Aini (2009). Islamin globaalit verkostot. Tampere: Vastapaino.

Mason, Gail (2006). Fear and hope: Author's response. Hypatia 21:2, 196-206.

Meer, Nasar \& Mouritsen, Per (2009). Political cultures compared. The Muhammad cartoons in the Danish and British Press. Ethnicities 9:3, 334-36o.

Mercer, Jonathan (2005). Rationality and Psychology in International Politics. International Organization 59:1, 77-106.

Mercer, Jonathan (2006). Human nature and the first-image: emotion in international politics. Journal of International Relations and Development 9:3, 288-303.

Miera, Frauke \& Pala, Valérie Sala (2009). The construction of Islam as a public issue in western European countries through the prism of the Muhammad cartoons controversy. Ethnicities 9:9, 383-408.

Moïsi, Dominique (2009). The geopolitics of emotions. How cultures of fear, humiliation, and hope are reshaping the world. New York: Doubleday.

Mythen, Gabe \& Walklate, Sandra (2006). Communicating the terrorist risk: Harnessing a culture of fear? Crime Media Culture 2:2, 123-142.

O'Neil, Saffron \& Nicholson-Cole, Sophie (2009). "Fear won't do it". Promoting positive engagement with climate change through visual and iconic representations. Science Communication 30:3, 355-379.

Oates, Sarah (2006). Comparing the politics of fear: The role of terrorism news in election campaigns in Russia, the United States and Britain. International Relations 20:4, 425-437.

Oates, Sarah (2007). The Neo-Soviet model of the media. Europe-Asia Studies 59:8, 1279-1297.

Olesen. Thomas (2009). The Muhammad cartoons conflict and transnational activism. Ethnicities 9:3, 409426.

Ost, David (2004). Politics as the Mobilization of Anger. Emotions in Movements and in Power. European Journal of Social Theory 7:2, 229-244.

Pain, Rachel (2009). Globalized fear? Towards an emotional geopolitics. Progress in Human Geography $33: 4,466-486$.

Porter, Elisabeth (2006). Can Politics Practice Compassion? Hypatia 21:4, 97-123.

Power, Mick \& Dalgleish, Tim (2008). Cognition and emotion. From order to disorder. Hove: Psychology Press.

Powers, Shawn (2008). Examining the Danish cartoon affair: mediatized cross-cultural tensions? Media, War Q Conflict 1:3, 339-359.

Ratner, Carl (2000). A Cultural-Psychological Analysis of Emotions. Culture Q Psychology 6:1, 5-39.

Refaie, Elisabeth (2009). Multiliteracies: how readers interpret political cartoons. Visual Communication $8: 2,181-205$.

Ridanpää, Juha (2009). Geopolitics of humour: The Muhammed cartoon and the Kaltio comic strip episode in Finland. Geopolitics 14:4, 729-749. 
Ross, Andrew (2006). Coming in from the cold: Constructivism and Emotions. European Journal of International Relations 12:2, 197-222.

Rostbøll, Christian F. (2009). Autonomy, Respect, and Arrogance in the Danish Cartoon Controversy. Political Theory 37:5, 623-648.

Sajid, Abduljalil (2005). Islamophobia: A new word for an old fear. Palestine-Israel Journal 12:2-3. Saatavilla: http://www.pij.org/details.php?id=344 (luettu 12.8.2010).

Sanadjian, Manuchehr (2006). Fear, terror and the new global economy of salvation - Global excess and 'suicide' bombing in London. Social Identities 12:6, 701-725.

Schinkel, Willem (2008). Contexts of anxiety. The moral panic over 'senseless violence' in the Netherlands. Current Sociology 56:5, 735-756.

Semmerling, Tim Jon (2008). Those "evil" Muslims! Orientalist fears in the narratives of the war on terror. Journal of Muslim Minority Affairs 28:2, 207-223.

Sharkey, Judy (2004). Lives stories don't tell: Exploring the untold in autobiographies. Curriculum Inquiry 34:4, 465-512.

Shirlow, Peter \& Pain, Rachel (2003). The geographies and politics of fear. Capital Q Class 27:2, 15-26.

Sløk, Camilla (2009). Here I Stand. Lutheran Stubbornness in the Danish Prime Minister's Office during the Cartoon Crisis. European Journal of Social Theory 12:2, 231-248.

Solomon, Robert C. (2007). True to our feelings. What our emotions are really telling us. Oxford: Oxford University Press.

Tangherlini, Timothy R. (2008). And the wagon came rolling in...: Legend and the politics of (self-) censorship in nineteenth-century Denmark. Journal of Folklore Research 45:3, 241-261.

Ulkomisteriö (2006). Le Monde: Muhammad-sarjakuvan kohtalo Suomessa muistuttaa suomettumisesta. Mediakatsaus, 2.3.2006. Saatavilla: http://formin.finland.fi/Public/Print.aspx?contentid=66o62\&nod eid=15145\&culture=fi-FI\&contentlan=1 (luettu 11.8.2010).

Weimann, Gabriel (2008). The psychology of mass-mediated terrorism. American Behavioral Scientist 52:1, 69-86.

Wilkins, Karin Gwinn (2009). Mapping fear and danger in global space: Arab Americans' and others' engagement with action-adventure film. International Communication Gazette 71:7, 561-576. 